\title{
Efficacy of an herbal preparation based on lovage, rosemary, and centaury on patients after extracorporal shockwave lithotripsy
}

\author{
Volodymyr Frankovych Vitkovskyy
}

\begin{abstract}
Study objective: To study the effect of a herbal preparation containing a standardised BNO 1040 extract* (based on lovage root, rosemary leaves and aerial parts of centaury) on the extracorporeal shockwave lithotripsy (ESWL) results in patients with urolithiasis (UL).

Methodology: 150 patients with UL (aged 18-65 years) treated with ESWL method were divided into 2 equal groups. The main group $(n=75)$ received standard recommendations and herbal preparation (12 months). The control group $(n=75)$ received standard recommendations only. The following was evaluated: time and degree of elimination of fragments; the presence of pain and leukocyturia; recurrent stone formation.

Results: The elimination of fragments was observed up to 14 days in $94.7 \%$ of patients in the main group versus $76 \%$ of patients in the control group. Renal colic was observed in $6.7 \%$ of patients in the main group versus $10.7 \%$ of patients in the control group; cases of leukocyturia were observed within 14 days in $10.7 \%$ versus $22.7 \%$, respectively. During the year, a recurrent lithiasis was diagnosed in $6.7 \%$ of patients in the main group and in $16 \%$ of patients in the control group.
\end{abstract}

Conclusion: The use of BNO 1040 extract in combination with ESWL: contributes to more rapid and safe elimination of fragments of the calculi and reduces the risk of recurrent stone formation.

Trial registration: DRKS ID 00021200. Registered retrospectively in German Clinical Trial Register 27.03.2020. https:// www.drks.de/

Keywords: Urolithiasis, Extracorporeal shockwave lithotripsy, Herbal therapy, BNO 1040 extract, Elimination of fragments, Recurrence, Ultrasound

\section{Introduction}

It is known that urolithiasis (UL) is a recurrent disease, and in some time, in $30 \%$ of patients the stone reappears in the urinary tract after its removal $[1,2]$. The reason is the existing metabolic disorders in patients with UL, heredity, and other endogenous and exogenous factors [1]. Despite the significant progress in the field of early diagnosis and treatment of UL the amount of patients with this pathology increases from year to year [2-4].

Correspondence: v.vitkovskyy@gmail.com

Department of Urology, assistant professor, Danylo Halytsky Lviv National Medical University, Lviv, Ukraine

\section{Springer Open}

The development of technical progress stimulates the introduction of new, even more up to date and less invasive methods of stones removing from the urinary tract, but that evolution does not stimulate the development of methods of metaphylaxis of recurrent stone formation. Rendering aid to the patient with UL development is incomplete, leads to undue economic losses, because it is known that it is better to prevent the disease than to treat. Economic aspects are important and are currently being actively discussed $[1,2]$.

One of the up to date and effective methods of treatment of patients with UL is remote or extracorporeal

(c) The Author(s). 2021 Open Access This article is licensed under a Creative Commons Attribution 4.0 International License, which permits use, sharing, adaptation, distribution and reproduction in any medium or format, as long as you give appropriate credit to the original author(s) and the source, provide a link to the Creative Commons licence, and indicate if changes were made. The images or other third party material in this article are included in the article's Creative Commons licence, unless indicated otherwise in a credit line to the material. If material is not included in the article's Creative Commons licence and your intended use is not permitted by statutory regulation or exceeds the permitted use, you will need to obtain permission directly from the copyright holder. To view a copy of this licence, visit http://creativecommons.org/licenses/by/4.0/. 
shock wave lithotripsy (ESWL). However, in this group of patients, the time of release from the fragments of the urinary tract takes time, and not in all cases there is the elimination of fragments of the destroyed stone in full $[5,6]$. Patients whose urinary tract is completely free of stone fragments without complications remain conditions for the formation of recurrent stones in the future $[7,8]$. It is known that ESWL, or other up to dated minimally invasive methods of active removal of stones from the urinary tract, cannot affect metabolic disorders in the body of a patient with UL and prevent recurrent stone formation. Accordingly, there are indications in concomitant therapy that may improve the efficacy of fragment release after ESWL treatment and at the same time reduce the risk of recurrent stone formation at different times after complete elimination of fragments. Phytopreparations can be used for concomitant, longterm therapy, namely a preparation containing BNO 1040 extract which is registered as an herbal medicine in 28 countries, including Germany and Ukraine called Canephron $^{\circ} \mathrm{N}$ drops containing Centaurii herb, lovage root (radix Levistici) and rosemary leaf (folia Rosmarini).

Canephron $^{\circ} \mathrm{N}$ has a complex of effects which can affect both the efficacy of the elimination of urinary calculi fragments after lithotripsy [5, 9], as well as nonspecific stone formation factors: reduction in urine saturation with stone-forming substances; increase in urine magnesium ions concentration which is a natural crystallization inhibitor [10]; influence on indirect factors of calculus formation (inflammation, disturbance of the urodynamics, etc.).

Currently, there is considerable experience in the use of a herbal preparation containing BNO 1040 extract both for treatment and metaphylaxis of UL [11, 12]; however, a number of studies, which have studied the effects of a herbal preparation containing BNO 1040 extract in the complex treatment of patients with UL using ESWL and prevention of recurrent UL is limited.

\section{Study objective}

to study the ability of a herbal preparation containing BNO 1040 extract to enhance the treatment efficacy in patients with UL using extracorporeal shockwave lithotripsy and to prevent recurrent stone formation in these patients within the first year after complete elimination of fragments.

\section{Materials and methods Study design}

our study was an open label, monocentric, prospective comparative (in parallel groups) interventional, randomized study. To achieve the objective, we selected 2 groups of 75 patients with UL (aged 18-65 years) diagnosed with calcium oxalate urolithiasis and single stones of approximately the same size localized in the kidneys and ureters. The study compared the results of treatment with a herbal preparation containing BNO 1040 extract (main group) in combination and traditional prescriptions for treating patients with UL using ESWL compared to patients (control group) received traditional prescriptions only for treating patients with UL using ESWL (Table 1).

According to the standard of care, all patients underwent a full urological examination before treatment: total blood count, urinalysis with microscopy, urinary $\mathrm{pH}$ measurement (before, during and after treatment); biochemical blood analysis, plain urography (+ after treatment); ultrasonography of the kidneys, ureters, and bladder (before, during and after treatment).

Table 1 The study groups within the study for 12 months

\begin{tabular}{|c|c|c|c|}
\hline Group & Medicinal measures & Dosage & Duration \\
\hline $\begin{array}{l}\text { Treatment group } \\
(n=75)\end{array}$ & $\begin{array}{l}\text { - Diet } \\
\text { - ESWL } \\
\text { - Adequate fluid intake } \\
\text { - Herbal preparation containing BNO } 1040 \text { extract } \\
\text { - Antispasmodic drug (drotaverine hydrochloride) } \\
\text { - Painkillers (Dexketoprofen), antispasmodics in case of } \\
\text { pain syndrome. } \\
\text { - Exercise therapy }\end{array}$ & $\begin{array}{l}\text { Daily } \\
1 \text { session of ESWL, the } 2 \text { nd session if } \\
\text { required } \\
2-3 \text { I per day } \\
2 \text { tablet/50 drops } 3 \text { times a day } \\
\text { According to instructions } \\
\text { According to instructions } \\
\text { Daily }\end{array}$ & $\begin{array}{l}\text { Long-term } \\
\text { Single } \\
\text { Long-term } \\
\text { During elimination } \\
\text { of fragments and for } 6 \\
\text { months } \\
\text { During elimination } \\
\text { of fragments } \\
\text { Occasionally } \\
\text { single } \\
\text { Daily }\end{array}$ \\
\hline $\begin{array}{l}\text { Control group }(n= \\
75)\end{array}$ & $\begin{array}{l}\text { - Diet } \\
\text { - ESWL } \\
\text { - Adequate fluid intake } \\
\text { - Antispasmodic drugs } \\
\text { - Painkillers, antispasmodics in case of pain syndrome. } \\
\text { - Exercise therapy }\end{array}$ & $\begin{array}{l}\text { daily } \\
1 \text { session of ESWL, } \\
\text { the } 2 \text { nd session if required } \\
2-3 \text { I per day } \\
\text { According to instructions } \\
\text { According to instructions } \\
\text { Daily }\end{array}$ & $\begin{array}{l}\text { Long-term } \\
\text { Single } \\
\text { Long-term } \\
\text { During elimination of } \\
\text { fragments } \\
\text { Occasionally } \\
\text { single } \\
\text { Daily }\end{array}$ \\
\hline
\end{tabular}


Table 2 Allocation of patients according to age

\begin{tabular}{llllll}
\hline Parameter & Group & \multicolumn{2}{l}{ Statistical indicators } \\
\cline { 3 - 6 } & & $\mathbf{n}$ & $\mathbf{M} \pm \mathbf{S D}$ & $\boldsymbol{p}$-value & Homogeneity of the groups* \\
\hline Age, & The Main group & 75 & $39.5 \pm 5.7$ & 0.071 & Homogeneous \\
years & The Control group & 75 & $41.1 \pm 5.5$ & &
\end{tabular}

*The conclusion is drawn at the significance level of 0.05

\section{Study population}

Patients (male and female) aged 18-65 years diagnosed with UL (calcium oxalate urolithiasis) after ESWL 150 patients with stones of approximately the same size and localization, preserved kidney function. ESWL was performed on Dornier Compact Sigma Lithotripter. The main group consisted of 75 patients as well as the control group $(n=75)$. Distribution between groups was carried out with randomly numbered envelopes.

\section{Inclusion criteria}

The main inclusion criterion was a proven diagnosis of calcium oxalate urolithiasis with an existing single stone of $0.8-1.3 \mathrm{~cm}$ in the kidneys and of $0.5-0.9 \mathrm{~cm}$ in the ureter; the age of $18-65$ years and the consent to participate in the study. The chemical composition of the calculus was predicted according to data on the urine microscopic examination, urine $\mathrm{pH}$, plain radiography before treatment, and according to the X-ray diffraction analysis after elimination of the fragments.

\section{Exclusion criteria}

- Commonly accepted contraindications to treatment with ESWL;

- Long-term obstruction of the urinary tract with a stone and pronounced impairment of renal excretory function;

- Diabetes mellitus;

- Immunodeficiency states;

- Severe concomitant somatic pathology which can have a significant effect on the treatment of UL using ESWL method;

- Calculus size is more than $1.3 \mathrm{~cm}$;

- Another chemical composition of urolithiasis (phosphates, urates, struvites).

\section{Study methodology}

During the study period, patients had 6 visits: Visit 1 (Day 1) - ESWL procedure + recommendations and prescription of drug treatment Table 1. In addition to drug treatment, patients were prescribed a diet aimed at preventing recurrent stone formation included: adequate water intake (2-3 l per day), limiting oxalates, oxalic and acetic acid, spicy, fried, fatty foods, in the diet, individual recommendations for nutrition, depending on the characteristics of the mineral metabolism disorder.

Visit 2 (Day 7) - result evaluation of the elimination of disintegrated calculi, diagnosis of complications or indications for repeated ESWL, if there are complications repeated ESWL is recommended; Visit 3 (Day 14) - result evaluation of disintegrated calculi, diagnosis of complications or indications for repeated ESWL, if there are complications repeated ESWL is recommended (determination of the percentage of patients with complete elimination of disintegrated stone fragments from the urinary tract); Visit 4 (Day 30) - evaluation of treatment results (percentage of patients with complete elimination of fragments from the urinary tract); Visit 5 (Day 45) final assessment of treatment results (percentage of patients with complete elimination of fragments from the urinary tract); Visit 6 (after a year) - evaluation of the possible recurrent stone formation.

From Visit 1 to Visit 6, the physician evaluated:

- Complaints, localization of pain, intensity, discomfort, impaired urination, etc.;

- Data of clinical and physical examination;

- Results of total blood count;

- Results of clinical urine analysis: urine $\mathrm{pH}$, level of leukocyturia;

- Data of ultrasound of the kidneys, ureters and bladder;

- Data of plain radiography.

\section{Efficacy endpoint}

The main efficacy endpoints were the following:

- no need for repeated sessions of ESWL procedure.

- no complications and no recurrent disease during the year.

\section{Safety criteria}

No adverse effects or adverse events while administering the study drug.

Table 3 Allocation of patients according to sex

\begin{tabular}{lllll}
\hline Parameter & Group & \multicolumn{3}{l}{ Statistical indicators } \\
\cline { 3 - 5 } & & $\mathbf{n}$ & Men & Woman \\
\hline Gender & Main & 75 & $39(52 \%)$ & $36(48 \%)$ \\
& Control & 75 & $41(54.7 \%)$ & $34(55.3 \%)$ \\
Total & & 150 & $80(53.3 \%)$ & $70(46.7 \%)$ \\
\hline
\end{tabular}


Table 4 distribution according to localization

\begin{tabular}{|c|c|c|c|c|c|c|c|c|c|c|c|c|c|c|c|}
\hline \multicolumn{8}{|c|}{ The treatment group $(n=75)$ with a herbal preparation containing BNO 1040 extract } & \multicolumn{8}{|c|}{ The Control group $(n=75)$} \\
\hline \multicolumn{2}{|c|}{ Pelvis } & \multicolumn{2}{|c|}{ Calix } & \multicolumn{2}{|c|}{ Proximal ureter } & \multicolumn{2}{|c|}{ Distal ureter } & \multicolumn{2}{|c|}{ Pelvis } & \multicolumn{2}{|c|}{ Calix } & \multicolumn{2}{|c|}{ Proximal ureter } & \multicolumn{2}{|c|}{ Distal ureter } \\
\hline$n$ & $\%$ & $\mathrm{n}$ & $\%$ & $\mathrm{n}$ & $\%$ & $\mathrm{n}$ & $\%$ & $\mathrm{n}$ & $\%$ & $\mathrm{n}$ & $\%$ & $\mathrm{n}$ & $\%$ & $\mathrm{n}$ & $\%$ \\
\hline 23 & 30.7 & 13 & 17.3 & 25 & 33.3 & 14 & 18.7 & 20 & 26.7 & 16 & 21.3 & 23 & 30.7 & 16 & 21.3 \\
\hline
\end{tabular}

\section{Data analysis}

The descriptive statistics methods were used to analyze homogeneity of the groups. Normality of the data distribution verifications in each group was performed for quantitative parameters using Shapiro-Wilk test. In the case of normal data distribution, the groups were compared by via the Student's test for independent samples. Mann-Whitney test was used for comparison of the groups if the data distribution was different from normal. The data were presented using descriptive methods. All results were expressed as quantities and percentages, if appropriate. Statistical comparisons were conducted using the Student's t test, with a two-sided 95\% confidence interval (95\% CI), $p \leq 0.05$.

\section{Results}

The average age of patients in the main group was 39.5 years; in the control group - 41.1 years (Table 2). Also, in both groups there was a slight prevalence of the number of men over women (Table 3). In other words, the groups did not differ from each other by age sex.

The average size of calculi in the kidneys was $1.0 \pm 0.3$ $\mathrm{cm}$, in the ureters $-0.7 \pm 0.2 \mathrm{~cm}$. Distribution of the patients depending on the location in the urinary tract is presented in the Table 4.

Before treatment, pain of various intensity and discomfort in the lower back (kidney localization zone) was observed in $86.7 \%$ of patients in the main group and in $80 \%$ in the control group. Leukocyturia was observed in $40 \%$ and $33.3 \%$ of patients, respectively. Urine $\mathrm{pH}$ in the main group was $6.1 \pm 0.5$; in the control group $-6.2 \pm 0.5$.

The total number of ESWL session, the shock waves per session and patients who had indications for a second procedure of ESWL in the main group was slightly less than in the controlled one. This difference had no statistical significance and was in the nature of tendency (Table 5). In all cases, after ESWL, the stone fragments were up to $<4 \mathrm{~mm}$ (according to the control ultrasonography and review radiography).

\section{Elimination of destroyed fragments}

During the following days of observation, there was a significant difference in the dynamics of elimination of destroyed fragments of urinary calculi.

Fig. 1 shows this indicator. Even though in our study, the complete elimination of destroyed calculi fragments was observed in all patients of both groups, we can conclude that this process occurred faster in the main group (Table 6). This difference is 2.42 days and is statistically significant $(p=0.011)$. Therefore, in the main group, the complete elimination of fragments from the urinary tract within 15 days amounted to $94.7 \%$. Only three patients (4\%) needed a longer period (up to 30 days) for the elimination of destroyed fragments and one patient - up to 45 days. In the control group, after 14 days, the complete elimination of fragments was observed only in $76 \%$ of patients; it is almost $20 \%$ less than in the main group. This difference is statistically significant $(p=0.042)$.

\section{Complications after ESWL}

After ESWL procedure, no severe complications were observed in any of the cases. During the period of elimination of urinary calculus fragments, pain of various intensity in the lumbar region of some patients was observed, and in some cases, renal colic was diagnosed ( 8 points or more according to the $0-10$ points visual analogue scale). For this reason, 32 patients in the main group and 34 in the control one received pain killers (dexketoprofen) in addition to the antispasmodic drugs (drotaverine hydrochloride). It is important to note that the proportion of such complications was lower in the main group compared with the control group in relation to the symptom "pain and discomfort" and leukocyturia. With respect to renal colic, there was also a difference,

Table 5 Characteristics of shockwave lithotripsy sessions in groups

\begin{tabular}{|c|c|c|c|c|}
\hline Parameter & Group & n & Value & $\mathbf{P}$ \\
\hline \multirow[t]{2}{*}{ Average number of hits per session } & The main group & 75 & $2450 \pm 350$ & 0.18 Non-significant \\
\hline & The control group & 75 & $2450 \pm 450$ & \\
\hline \multirow[t]{2}{*}{ Average number of DSWL sessions } & The main group & 75 & $1.14 \pm 0.11$ & 0.11 Non-significant \\
\hline & The control group & 75 & $1.18 \pm 0.13$ & \\
\hline \multirow[t]{2}{*}{ The number of patients, who needed a second session of ESWL } & The main group & 75 & 10 & Non-significant \\
\hline & The control group & 75 & 13 & \\
\hline
\end{tabular}




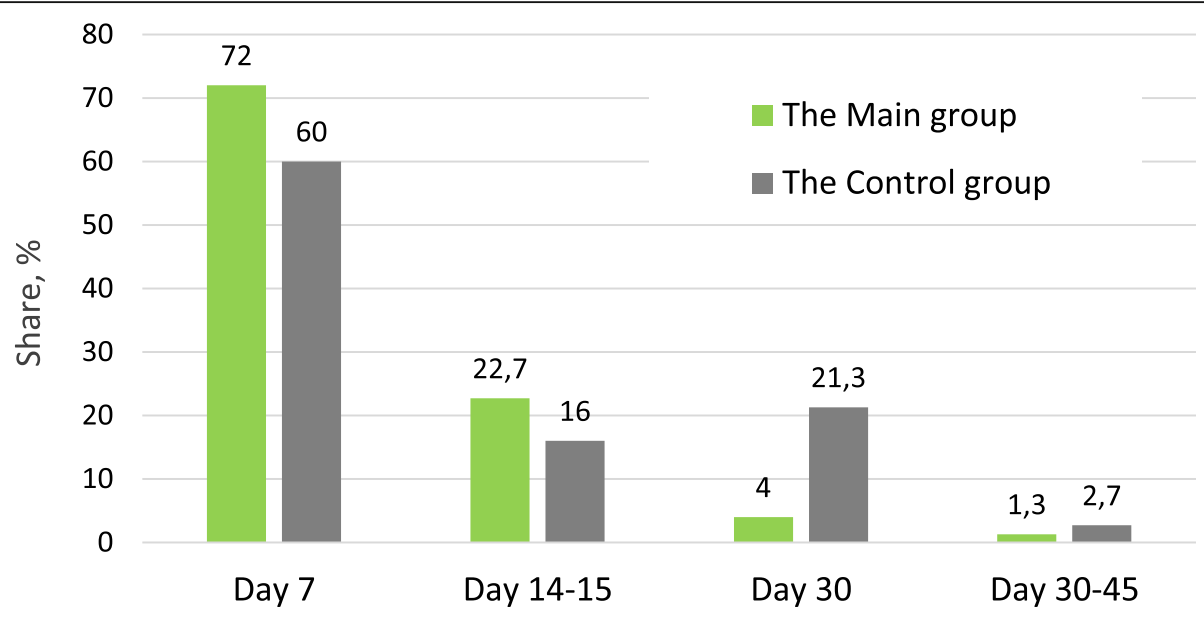

Fig. 1 Dynamics (\%) of elimination of destroyed fragments of urinary calculi in the groups

but it had no statistical significance and had a nature of tendency.

\section{Frequency of recurrent stone formation within a year after ESWL}

Within a year of patient follow-up, recurrent stone formation after elimination of calculi from the urinary tract was observed in 12 patients in the control group (16\%). In the main group, this indicator was significantly lower and amounted to 5 patients $(6.7 \%)$. However, due to a small number of studied events, it is impossible to talk about the significance of differences between the groups in relation to the frequency of recurrent stone formation (Fig. 2).

\section{Discussion}

Urolithiasis is a common and economically important disease, which is characterized by the formation of calculi of different chemical composition in the urinary tract. Despite the steady increase in the prevalence of this disease, the focus in modern medicine is on improving the methods of calculi removal and, to a lesser extent, conservative treatment $[13,14]$. At the same time, combining these two approaches can not only improve the efficacy of calculus removal techniques but also prevent recurrent stone formation $[15,16]$. A herbal preparation containing BNO 1040 extract is well suited for the role of one of the main plant components in the complex conservative treatment of UL. This medicinal product contains a fixed combination of herbal ingredients standardised in the composition of key biologically active substances of medicinal plants: aerial parts of centaury, lovage root and rosemary leaves. This combined composition provides a complex effect on the kidneys and urinary tract, which is expressed in moderate diuretic $[11,17]$ and antispasmodic action [18] which is the reason why the study drug improves urodynamics and contributes to a speedy elimination of calculi $[19,20]$. In this study, we also observed a speedy elimination of calculi fragments from the urinary tract. At the end of Week 2 after ESWL, the percentage of patients with complete elimination in the main group was $20.8 \%$ higher than in the control group.

Also, it should be noted that in the main group at the discharge of fragments observed $46.5 \%$ fewer cases of clinical manifestations, including pain of varying degrees in the projection of the kidneys and other parts of the abdominal cavity, indicating a good antispasmodic effect of BNO 1040 extract.

It was determined that in the main group in $56.5 \%$ of cases, patients had less leukocyturia than in the control group as a result of the anti-inflammatory effect of plant components in the composition of the herbal preparation containing extract BNO 1040 [11]. Plant components of BNO 1040 inhibit the development of pathogenic flora in the urine, which prevents the

Table 6 Analysis of groups by the time of passage of kidney stones after DSWL

\begin{tabular}{|c|c|c|c|c|c|c|c|}
\hline \multirow[t]{2}{*}{ Indicator } & \multirow[t]{2}{*}{ Group } & \multicolumn{6}{|c|}{ Statistical indicators } \\
\hline & & $\mathbf{n}$ & Arithmetical mean & Median & Standard deviation & Min & Max \\
\hline \multirow[t]{2}{*}{ Time of discharge of kidney stones after DSWL, days } & The main group & 75 & 9,81 & 5 & 7857 & 2 & 45 \\
\hline & The control group & 75 & 12,23 & 6 & 11,861 & 2 & 45 \\
\hline
\end{tabular}




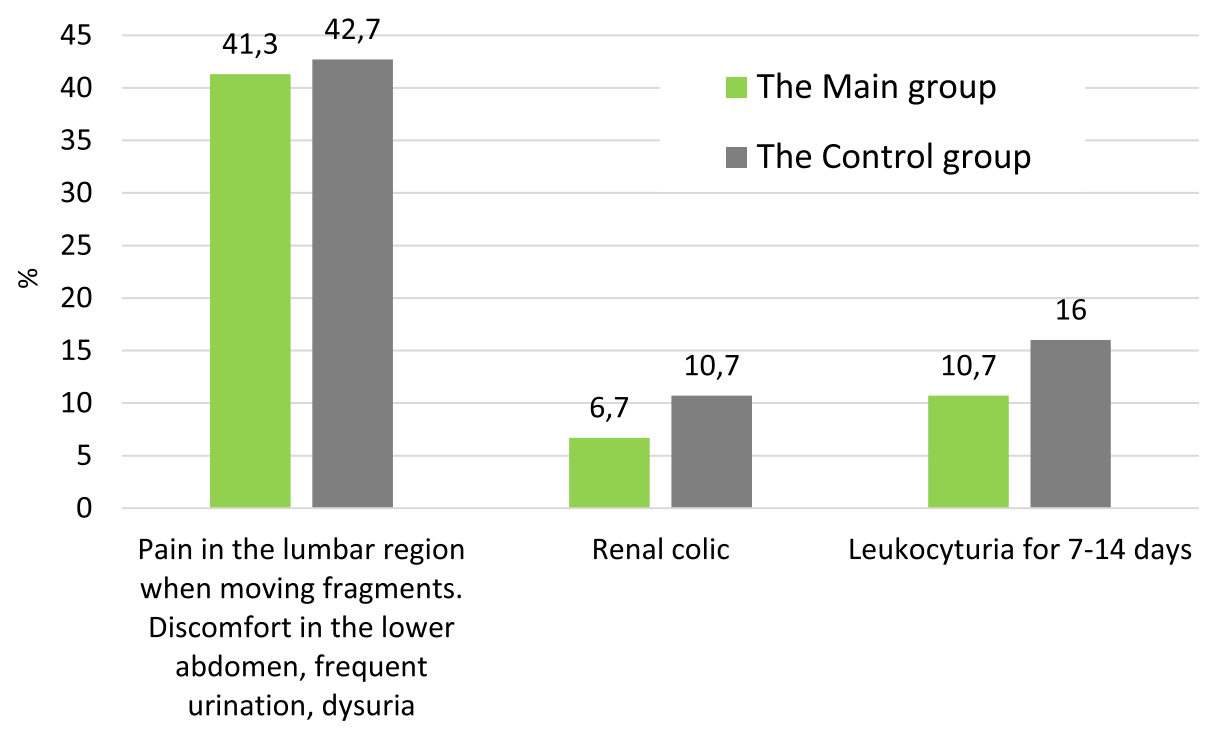

Fig. 2 Frequency of symptoms (\%) and complications in the study groups

exacerbation of inflammatory processes in the urinary tract during the elimination of fragments. All this contributes to a faster regression of the effects of kidney damage, the mucous membrane of the urinary tract from stones, fragments, and the direct impact of ESWL.

Directly phytopreparation containing BNO 1040 extract is a prophylactic to prevent recurrent stone formation, because it directly affects the following non-specific factors of stone formation: urine saturation with crystalforming substances; to increase the urine magnesium ions concentration (natural crystallization inhibitor); to influence the infectious inflammatory factors of urinary calculus formation. Thus, it is obvious that the use of a herbal preparation containing BNO 1040 extract as part of a complex therapy after ESWL accelerates the elimination of disintegrated calculi fragments from the urinary tract regardless of the level of their initial localization and reduces the number of such complications as pain and discomfort in the lower abdomen and renal colic attacks.

High tolerability and absence of adverse reactions in patients who have administered a herbal preparation containing BNO 1040 extract for a long time confirm its safety in use.

\section{Conclusion}

- A herbal preparation containing BNO 1040 extract is effective and safe in treatment of patients with urolithiasis treated with extracorporeal shockwave lithotripsy.

- The use of a herbal preparation containing BNO 1040 extract accelerates the elimination of stone fragments after extracorporeal shockwave lithotripsy and reduces the percentage of complications.

- The prescription of a herbal preparation containing BNO 1040 extract for 12 months after treatment with ESWL probably can help prevent early recurrent stone formation however, this aspect needs further study.

\section{Limitations}

The limitations of this study are absence of blinding and limited number of patients. The latter circumstance does not allow to obtain a statistically significant difference between the groups according to some of the studied parameters like: frequency of renal colic attacks during elimination of urinary calculus fragments, frequency of repeated stone formation within a year after ESWL.

\section{Abbreviations}

UL: urolithiasis; ESWL: extracorporeal shockwave lithotripsy; US: ultrasound examination; PR: plain radiography

\section{Acknowledgements \\ The author expresses his gratitude to the Bionorica SE company for providing scientific data on the studied drug, assistance in translating the article into English.}

Ethical approval and consent to participate

The study was conducted in accordance with Declaration of Helsinki [11] and ICH Harmonized Tripartite Guideline for Good Clinical Practice (CPMP) $\mathrm{ICH} / 135 / 95)$ [12]. Before the first patient was enrolled, the study protocol had been approved by the Local Ethics Committee. A written informed consent was obtained from all patients for any activities related to the study.

\section{Author's contributions}

All activities related to conducting of the study and writing an article was done by Volodymyr Vitkovskyi (W). The authors read and approved the final manuscript. 


\section{Author's information}

Vitkovskyi Volodymyr Frankovych, Associate Professor of the Department of Urology of Danylo Halytsky Lviv National Medical University, Urologist of the Department of Urology with the lithotripsy office in Lviv Regional Clinical Hospital.

Phone: + 38 (050) 5880025

e-mail: v.vitkovskyy@gmail.com

\section{Funding}

None.

\section{Availability of data and materials}

The datasets used and/or analyzed during the current study are available from the corresponding author on reasonable request.

\section{Consent for publication}

Not applicable.

\section{Competing interests}

The author declare that they have no competing interests regarding the publication of this paper.

Received: 27 March 2020 Accepted: 11 January 2021

Published online: 20 January 2021

\section{References}

1. Keoghane, S., Walmsley, B., Hodgson, D. (2009). The natural history of untreated renal tract calculi. BJU international, 105 (12), 1627-1629. Doi: http://doi.org/https://doi.org/10.1111/j.1464-410x.2010.09389.x.

2. Aliaev Yu G, Rudenko Vl. Modern aspects of drug therapy of patients with urolithiasis. Effective pharmacotherapy - Urology and nephrology. 2016; 5(41):10-6.

3. Aliaev Yu. G., Amosov A. V., Gazimiev M. A. Ultrasound methods of functional diagnostics in urological practice. M: "R.Valent". 2010

4. Cherepanova E, Dzeranov N. Metaprophylaxis of urolithiasis in ambulatory patients. Men's Health. 2014;4(55):96-100.

5. Davidov MI, Igoshev AM. The effect of herbal preparation Canephron N on the results of extracorporeal shockwave lithotripsy. Men's Health. 2015;4(55): 96-100.

6. Ceban E. Efficacy of a fixed combination of Centaurii herba, Levistici radix and Rosmarini folium in urinary lithiasis Zeitschrift für Phytotherapie. 2012; 33(01):19-23.

7. Tiselius H-G, Alken P, Buck C, Gallucci M, Knoll T, Sarica K, Türk C. EAU Guedlines on urolithiasis. European Association of Urology. 2009;116.

8. Kok, D. J. (2015). The preventive treatment of recurrent stone-formation: how can we improve compliance in the treatment of patients with recurrent stone disease? Urolithiasis, 44 (1), 83-90. Doi: http://doi.org/ https://doi.org/10.1007/s00240-015-0842-9.

9. Aliaev R. A herbal preparation Canephron $\mathrm{N}$ in the treatment of patients with urolithiasis. Urology. 2012:6:22-5.

10. Gaibulaev A, Kariev S. Effect of long-term Canephron N treatment on urinary risk factors associated with idiopathic calcium urolithiasis. Springer Medizin 2012.

11. Naber, K. (2013). Efficacy and safety of the phytotherapeutic drug Canephron $\mathrm{N}$ in prevention and treatment of urogenital and gestational disease: review of clinical experience in Eastern Europe and Central Asia. Research and reports in urology, 5, 39-46. Doi: http://doi.org/https://doi. org/10.2147/rru.s39288

12. Grigorian V, Amosov A. The use of Canephron N in urolithiasis. Russian Medical Journal. 2011;16:1033.

13. Alelign, T., Petros, B. (2018). Kidney stone disease: an update on current concepts. Advances in urology, 2018, 1-12. Doi: http://doi.org/https://doi. org/10.1155/2018/3068365.

14. Strohmaier, W. L. (2000). Volkswirtschaftliche Aspekte des Harnsteinleidens und der Harnsteinmetaphylaxe. Der Urologe A, 39 (2), 166-170. doi: http:// doi.org/https://doi.org/10.1007/s001200050026

15. Yeni, E et. al. (2003) 2 EULIS meeting (the 10-th European symposium on Urolithiasis). Istanbul, 348

16. Trinchieri, A. (2006). Epidemiological trends in urolithiasis: impact on our health care systems. Urological research, 34 (2), 151-156. Doi: http://doi.org/ https://doi.org/10.1007/s00240-005-0029-x.
17. Kumarasamy, Y., Nahar, L., Sarker, S. (2003). Bioactivity of gentiopicroside from the aerial parts of Centaurium erythraea. Phytotherapy, 74 (1-2), 151154. Doi: http://doi.org/https://doi.org/10.1016/s0367-326x(02)00319-2.

18. Ukhal M, Gabchak R. The use of the drug Canephron N in combination with balneotherapy in patients with urolithiasis. Men's Health. 2010;4:117-21.

19. Ukhal M., Malomuzh O., (2013). Modern possibilities of phytotherapy in the postoperative rehabilitation treatment of patients with urolithiasis complicated by chronic pyelonephritis. Urology, nephrology, Andrology. Kharkov, 196-200.

20. Gracza, L., Koch, H., Löffler, E. (1985). Über biochemisch-pharmakologische Untersuchungen pflanzlicher Arzneistoffe, 1. Mitt. Isolierung von Rosmarinsäure aus Symphytum officinale und ihre anti-inflammatorische Wirksamkeit in einem In-vitro-Modell. Archiv Der Pharmazie, 318 (12), 1090 1095. doi: http://doi.org/https://doi.org/10.1002/ardp.19853181207.

\section{Publisher's Note}

Springer Nature remains neutral with regard to jurisdictional claims in published maps and institutional affiliations.

\section{Submit your manuscript to a SpringerOpen ${ }^{\circ}$ journal and benefit from:}

- Convenient online submission

- Rigorous peer review

- Open access: articles freely available online

- High visibility within the field

- Retaining the copyright to your article

Submit your next manuscript at $\boldsymbol{\nabla}$ springeropen.com 